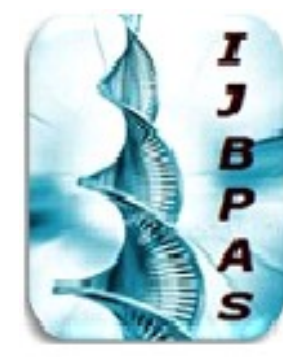

International Journal of Biology, Pharmacy and Allied Sciences (IJBPAS)

'A Bridge Betueen Caboratory and QRendo'

WWW.ijbpas.com

\title{
AN OPERATIONAL OVERVIEW OF INTEGRATED SOLID WASTE MANAGEMENT PROCESSING AND DISPOSAL
}

\section{POONKUNDRAN T*}

Dept. of Civil Engineering, Faculty of Engg. \& Tech., Annamalai University, Annamalai

Nagar, Tamil Nadu- 608002

*Corresponding Author Email: geepo076@rediffmail.com

Received $9^{\text {th }}$ Dec. 2019; Revised $6^{\text {th }}$ Jan. 2020; Accepted $8^{\text {th }}$ Feb. 2020; Available online $1^{\text {st }}$ Aug. 2020

https://doi.org/10.31032/IJBPAS/2020/9.8.4965

\begin{abstract}
The waste generated from the households or commercial establishment except industries and healthcare facilities is termed as municipal solid waste. The waste might be solid or semisolid in nature depending on the level of moisture. It includes domestic wet (biodegradable) $\&$ dry waste (recyclables and domestic hazardous waste) and treated biomedical waste too. Anyhow, hazardous industrial waste shall be exempted from inclusion in municipal solid waste (MSW).

Due to the widespread source of generation and heterogeneouscharacteristics, decentralize management of MSW is a mammoth task. Contrarily, centralized management with the integrated approach is of utmost convenience but attributes ancillary challenge in the form of waste quantity, malodour etc. Therefore, scientific planning and pertinent execution is necessary.

Another additional challenge of handling MSW is timelessness. The generation is consistent and the service also needs to be provided in a timely manner to avoid any risk. Thus the operations of waste management industries are around-the-clock. Hence additional backup of manpower and machinery is mandatory, which causes additional economic burden.

Moreover, the economic profitability is utterly questionable due to facts such as market acceptability of the products, lower market rate in comparison to the competing products, transportation charges, and growing rivalry.
\end{abstract}


Anyhow, the scenario is much more relaxing in the case of public private-partnership (PPP) joint ventures. Private operators receive a fixed amount against the waste load processed as thetipping fee and the amount may vary between Rs. 700- 900 per ton. Thereby assuring the financial suitability for the service provider.

Keywords: municipal solid waste, domestic hazardous waste, compost, refuse derived fuel, operational profitability

\section{INTRODUCTION}

Components of Solid Waste integrated facility with full-fledged

\section{Management}

There are two primary components of solid waste management (SWM) namely, Collection \& Transportation (C\&T) and Processing \& Disposal (P\&D). C\&T can be further classified into three subcomponents: primary, secondary, and tertiary system. Anyhow, the prior-mentioned categories are applicable based on the extent of the service area, quantity of waste generation, financial viability etc. In the case of lightly crowded towns with a population of 5 lakh or less, primary collection followed by landfill is generally practised. Because establishing a P\&D facility for treating 250 tons/ day is not economically recommended. Whereas, moderately crowded cities with a population range of 10 to 15 lakhs produces approx. 700 tons of waste on a regular basis. A small facility over an area of 75 acres with the facility of segregation, composting, and landfilling can be established. On the other hand, large metropolitan cities with a population range of 1-1.5 Cr. produces approx. 6000 tons/day of solid waste. Therefore an operations include: segregation, composting, refuse derived fuel (RDF) preparation, waste to energy (WtE), plastic recycling, landfilling, and leachate treatment is recommended [1-4]. Cities like Delhi, Mumbai, and Hyderabad have established such integrated P\&D facilities over an average footprint of 250 acres or more in PPP mode and operating since 2012 or lately $[\mathbf{5 , 6 ]}$.

\section{Collection \& Transportation}

The foremost segment of SWM is C\&T. Primary collection incorporates a door to door (DtD) collection system through handcarts, tricycles, small vehicles, etc. and accumulating it in community bins. The next step secondary collection involves transportation of waste from community bins to transfer station (TS) through medium size vehicles when the distance of the P\&D facility exceeds $10 \mathrm{~km}$ from the point of generation. The final segment of C\&T is tertiary transportation which incorporates the movement of compacted waste from TS to the P\&D facility in large covered vehicles and compactors. 


\section{Segregation}

Source segregation is the auxiliary component of C\&T and rampant in India since the recent past. The component comes at the top of the hierarchy and is the primary operation. It supposed to be done at the household level. As instructed in SWM rule 2016, domestic waste should be segregated into wet and dry waste categories in green and blue colour bin respectively [7, 8]. Furthermore, the segregated waste supposed to be collected separately from DtD basis either in separate collection vehicles or in a single vehicle with dedicated compartments for dry and wet waste storage.Source segregation can further help the P\&D facilities to reduce the operational expenditure (OPEX) (i.e. manpower cost, consumables etc.) and provide better yield, and quality of the product.

\section{Processing \& Disposal}

The later part of SWM is $\mathrm{P} \& \mathrm{D}$. As per World Bank statistics, in India only approx. $38 \%$ of $\mathrm{MSW}$ is collected and $9 \%$ is processed [9]. Remaining ends up in either open dumping \& burning or illegal burial. Therefore the matter seeks serious concern from both public and private agencies. There are few big cities named above are having scientific $P \& D$ facility but it's still far from reality in the case of small to a mediocre range of towns. Therefore the waste management sector possesses a great business potential and can open a window for mediocre entrepreneurial ventures with a long-term solution to India's unemployment issue.

\section{Verification}

The primary step of $\mathrm{P} \& \mathrm{D}$ is inspection. All the incoming waste should be verified manually or by online mean through CCTV and programmed logic control (PLC) system. Recent advancement like artificial intelligence system of infrared photography method can be adopted when high segregation efficiency is required. Items acceptable under SWM 2016 rule, shall be sent for further processing and the unauthorized items such as untreated biomedical waste, slaughterhouse waste, hazardous industrial waste, etc. should be sent back to the concerned authority for proper disposal.

\section{Quantification}

Weighing is the next step to follow. The weight of the waste can be obtained by subtracting the vehicle weight from the total load. Indian MSW comprises approx. $40-50 \%$ moisture and therefore the weight gets reduced with exposure to heat/ sunlight and time. Hence it's very crucial to weight the fresh waste from the billing point of view in the case of PPP operation. Moreover, MSW quantification shall be always done against the weight, not the volume. Because the volume of MSW varies between $620 \mathrm{~kg} / \mathrm{m}^{3}$ to $700 \mathrm{~kg} / \mathrm{m}^{3}$ 
based on the level of moisture. Further, it may lead to a huge variation between the point of generation and the $P \& D$ facility while handling mammoth quantities (Figure 1).

\section{Pre-sorting}

Waste is first tipped at pre-segregation area and subjected to sunbath curing for removal of excessive moisture. Otherwise, it may hamper the trammelling operation. Mostly, after $48 \mathrm{~h}$ of exposure, the waste is fed to 70-100 mm mesh size trammel for primary segregation of compostable and combustible fraction. The mesh size determination is a crucial phenomenon and needs to be finalized based on the composition of local MSW. More the waste is organic in nature, less should be the mess size and vice versa (Figure 2).

\section{Composting}

After pre-sorting, the organic fraction needs to be composted either by windrow or aerated static pile (ASP) composting. Windrow mechanism is largely recommended across the nation for handling the huge quantity. Waste is first arranged in layers to form trapezoidal heaps and effective microorganisms should be sprayed on the top of each layer. The shape is so chosen to maximize the surface area. The heap is maintained over a period of 27 days and should be turned once a week. Temperature, oxygen level, etc. shall be monitored once a week. Upon the completion of the regular maturity period, the material shall be tested to analyse the quality. Based on the report received, further screening and curing shall be done. The final product should be below $4 \mathrm{~mm}$ of particle size and $\mathrm{C} / \mathrm{N}$ ratio should be below 20 as per the guideline of Fertilizer Control Order (FCO).

Aerated static pile composting generally yields a better quality of compost in a shorter duration. Blended materials need to be placed in stationary or static piles. Piles shall be constructed over an air supply source like perforated plastic pipe. A $10 \mathrm{~cm}$ layer of non-corrosive bulk material such as wood chips or trammel reject from $20 \mathrm{~mm}$ screen shall be placed underneath. The compostable material can be placed on the top of the above. The pile height should be decided considering the following factors: porosity of local MSW and climatic condition. In general, a pile height of 1.5 to $2.5 \mathrm{~m}$ is practised. Additional height of 0.5 $\mathrm{m}$ is recommended for colder regions to maintain pile temperature. Further insulation can be provided by incorporating a 15 to $20 \mathrm{~cm}$ thick finished or bulking material layer if necessary. The protective layer also nullifies drying, vector movement, odour problem etc. and insulates the pile against temperature decrement (Figure 3, 4) [10, 11]. 


\section{RDF Preparation}

The combustible fraction is comparatively easier to process and only requires mechanical processing. Segregated combustible fraction (SCF) shall be first de-moisturized and then micronized to meet the basic quality standards prescribed by ASTM or CPHEEO. Further segregation of the material is done based on the weight via air density separator. The light fraction mostly comprises plastics and light cloths, whereas the heavy fraction includes coconut coir, jute, rexine, leather, etc. The metals need to be separated from the stream by magnetic and eddy current separator respectively. Additionally, inert such as glass and stone pieces should be removed manually. The final RDF grade needs to be decided based on the calorific value of the product and can be utilised internally in the case of an operational WtE plant within the same facility. Else can be sold to the nearby cement industry with alternate fuel consumption kiln (Figure 5) [11].

\section{Waste to Energy Recovery}

Incineration based system is most common for energy recovery option from MSW. There are two major technologies of incineration widely adopted across the world namely: grate based incinerator and fluidized bed incinerator. The waste is burnt at a temperature range of $900^{\circ} \mathrm{C}$ $1100^{\circ} \mathrm{C}$ to avoid the generation of dioxin and furan. Once the boiler water gets heated the turbine runs with the help of vapour and produced power is stored in grids. The flue gas stream is also purified in the process before releasing in the open atmosphere. A set of operations such as lime-milk scrubbing, superheating, and baghouse filtration is performed to ensure zero toxic discharge. Ramky's WtE incinerator located at Delhi facility is the country's first WtE plant of $24 \mathrm{MW}$ capacity and the other plant is yet to commission by early 2020 at Hyderabad of similar capacity (Figure 6) [12].

The other way of energy recovery through MSW involves anaerobic digestion (AD). The process can be run on both solo and combined organic feedstocks digestion system like vegetable market waste, food waste, septage, bio-leachate, etc. The yield could be as high as $60 \mathrm{~m}^{3}$ of biogas from 1 ton of waste per day. The fresh biogas generated from the system also contains impurities such as water vapour, $\mathrm{H}_{2} \mathrm{~S}, \mathrm{NH}_{3}$, etc. which may hamper the heating value. Therefore impurities need to be removed and compressed biogas (CBG) can be produced. It can be fed to the gas engine to convert it to power or consumed as such for cooking (Figure 7) [13].

\section{Plastic Recycling}

The recyclables such as glass bottles, metals, plastics, paper needs to be segregated and should be processed separately. Glass needs to be broken, 
melted, and re-casted. Metals can be sold to authorized recyclers for re-consumption in the manufacturing process. Plastics can be separated into categories such as LDPE, HDPE, and PP and need to be processed separately. The operation includes washing, drying, agglomeration, extrusion, and palletisation. The granules can be further used in making of blowing film bags, mats, and other furniture by injection moulding (Figure 8) [14].

\section{Landfilling}

All the process inert and non-recyclables should be securely disposed-off in the sanitary landfill. It may be of three categories: above ground, underground, or a combination of both. The bed of the landfill should be constructed with the utmost care to avoid any future infiltration and contamination. The bottom layer should be of single liner system with geosynthetic clay liner (GCL), high-density polyethylene (HDPE) liner of $2 \mathrm{~mm}$ thickness, drainage layer made of coarse aggregate, etc. Each cell should be operated and closed on a regular basis. Once the landfill capacity gets over the same should be closed with a similar orientation of liners. Gas and leachate collection system needs to be installed to eliminate the safety hazard. Ultimately, it should be covered with a layer of topsoil and vegetative cover. Post closure maintenance is another important aspect to ensure the longevity of the landfill (Figure 9).

\section{Leachate Treatment}

The final component of $P \& D$ is leachate treatment. The areas such as the tipping floor, windrow platform, RDF processing area, landfill, etc. produces a huge amount of bio-leachate on a regular basis. The concentration of pollutants such as TDS, BOD, and COD is typically high in MSW leachate and thus primary treatment and biological treatment with concomitant energy recovery is a feasible option. Further, a tertiary unit comprises activated carbon filter, micro/ultrafiltration, reverse osmosis (RO), multiple-effect evaporator (MEE), and agitated thin film dryer (ATFD) can maximize the water recovery up to $80 \%$ or more and thereby enhancing the landfill life. The filtrate can be utilized to develop the greenbelt or for any other farming works. But the salt generated from both MEE and ATFD is of hazardous nature and shouldn't be disposed of in the sanitary landfills. It needs to be sent to the nearby industrial waste management (IWM) facility for the ultimate disposal in the secured landfill after suitable stabilization if required [6]. 


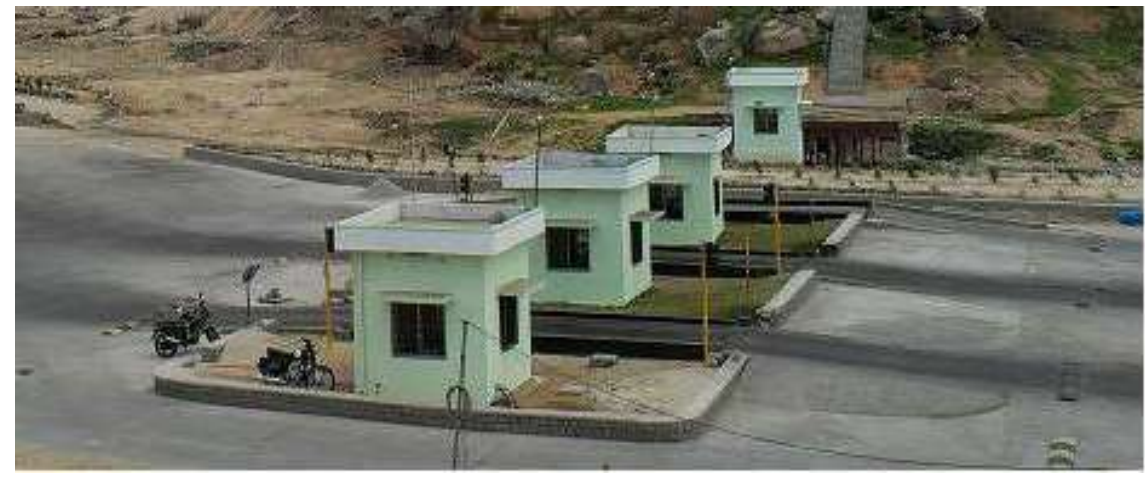

Figure 1: Weigh Bridge at HiMSW P\&D facility Hyderabad

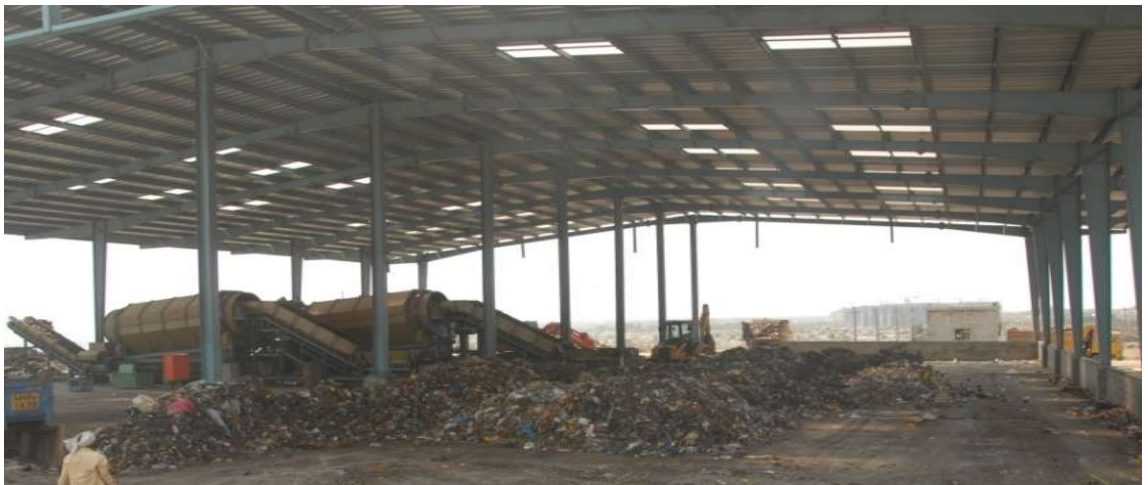

Figure 2: Pre-sorting area at HiMSW P\&D facility Hyderabad

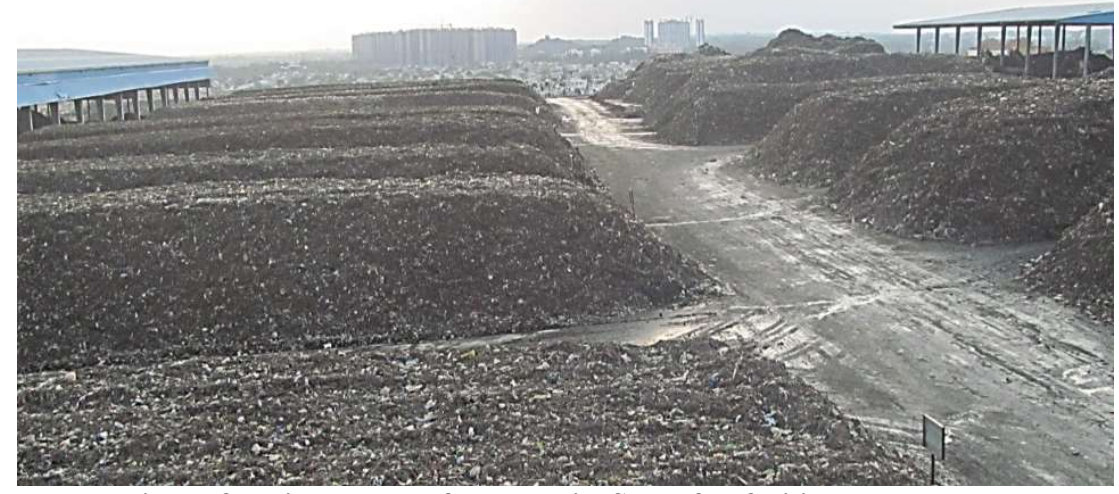

Figure 3: Windrow platform at HiMSW P\&D facility Hyderabad

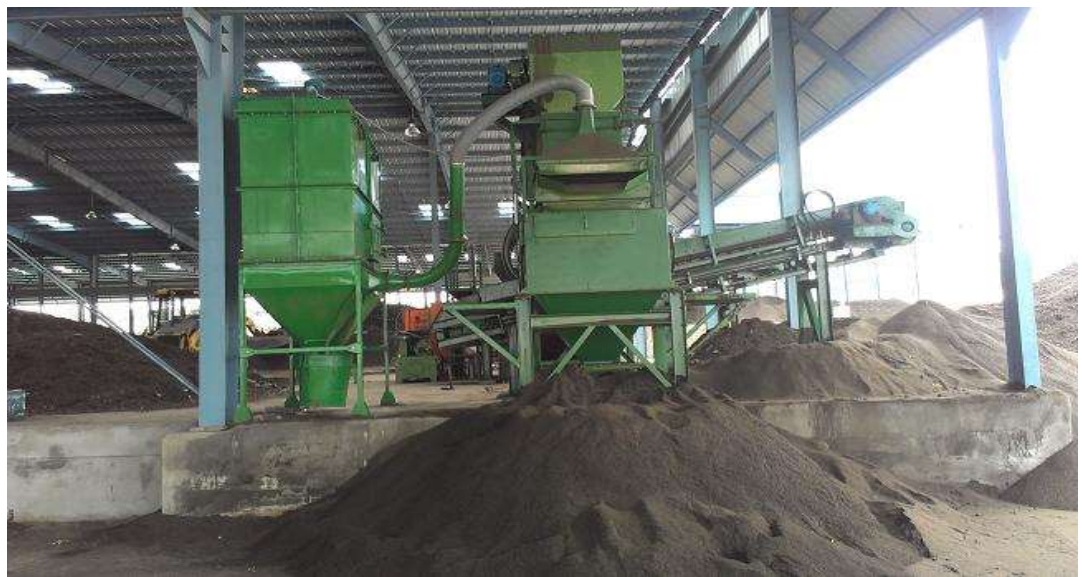

Figure 4: Blending of finished compost at HiMSW P\&D facility Hyderabad 


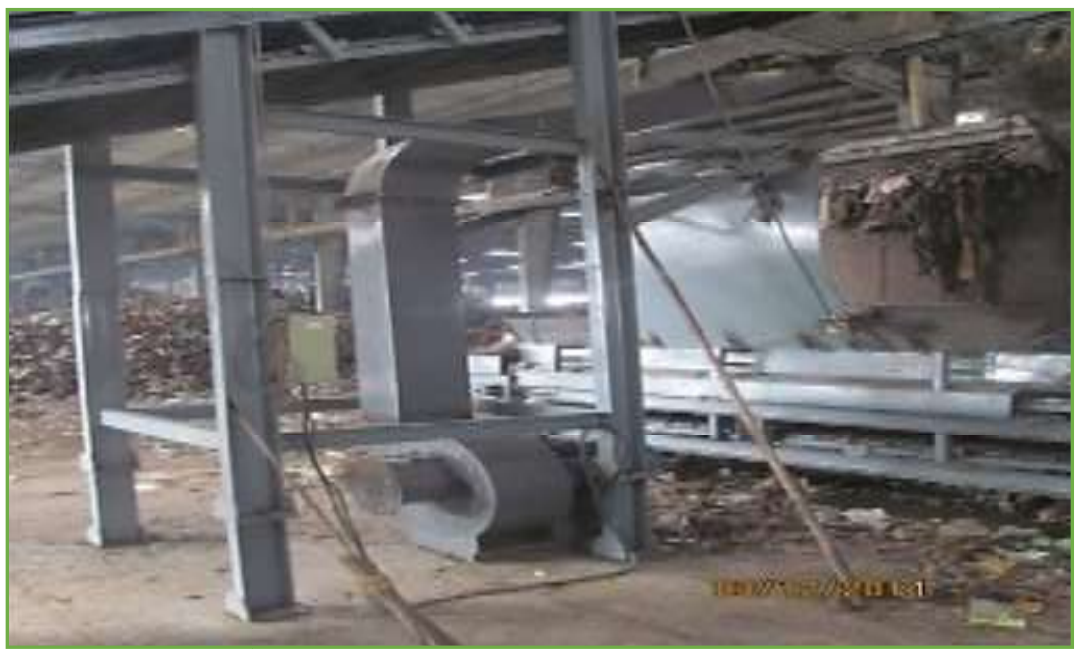

Figure 5: RDF processing plant at HiMSW P\&D facility Hyderabad

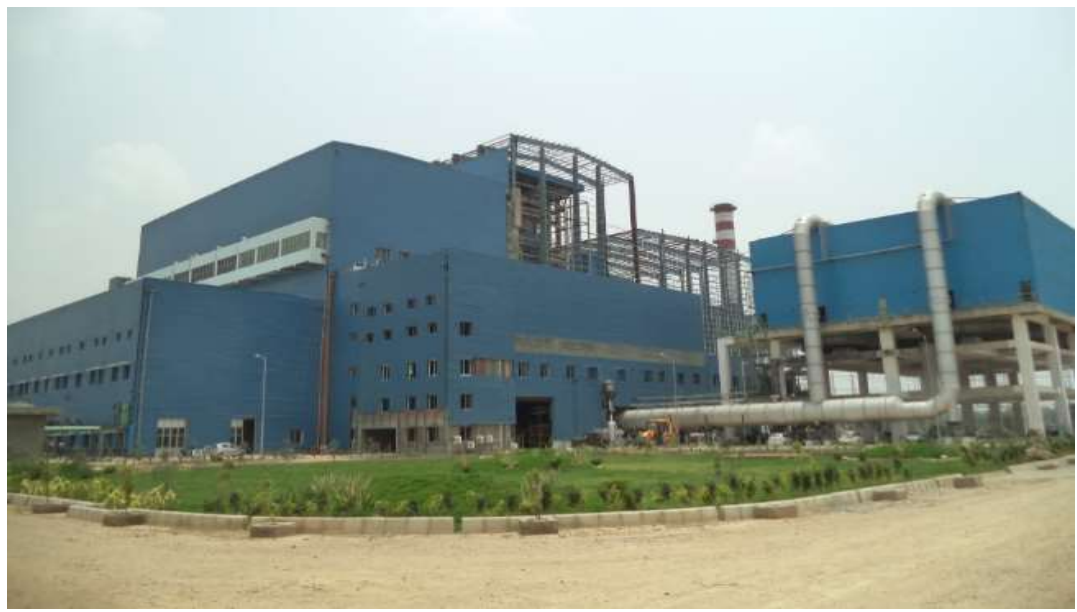

Figure 6: Incineration based WtE plant at Delhi P\&D facility of Ramky group

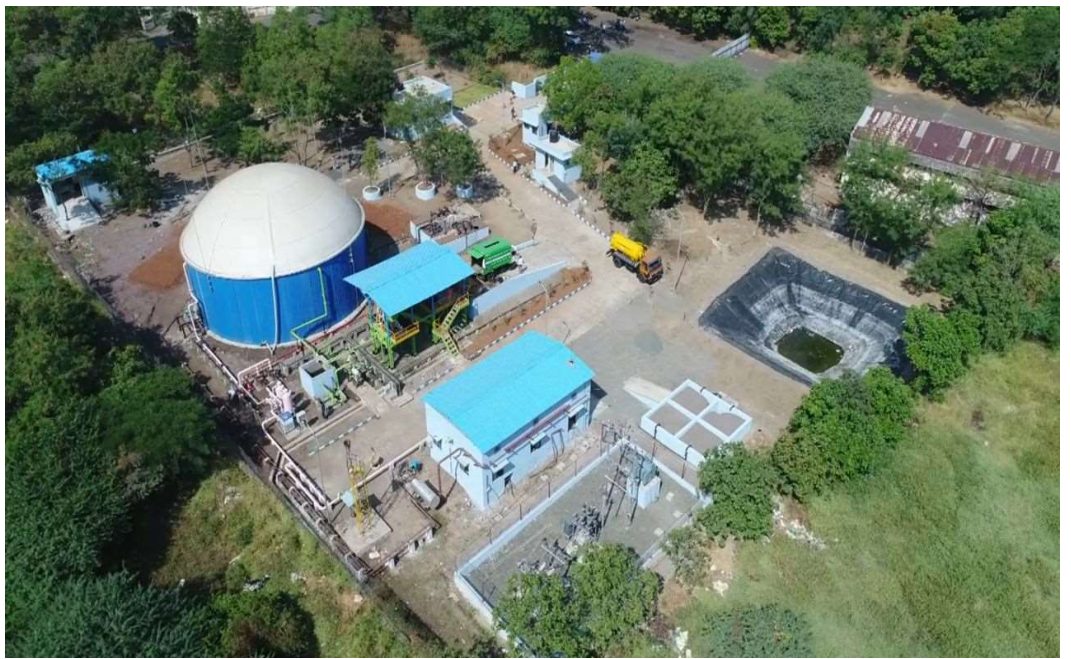

Figure 7: Anaerobic digestion based WtEbiomethanation plant at Chennai of Ramky group 


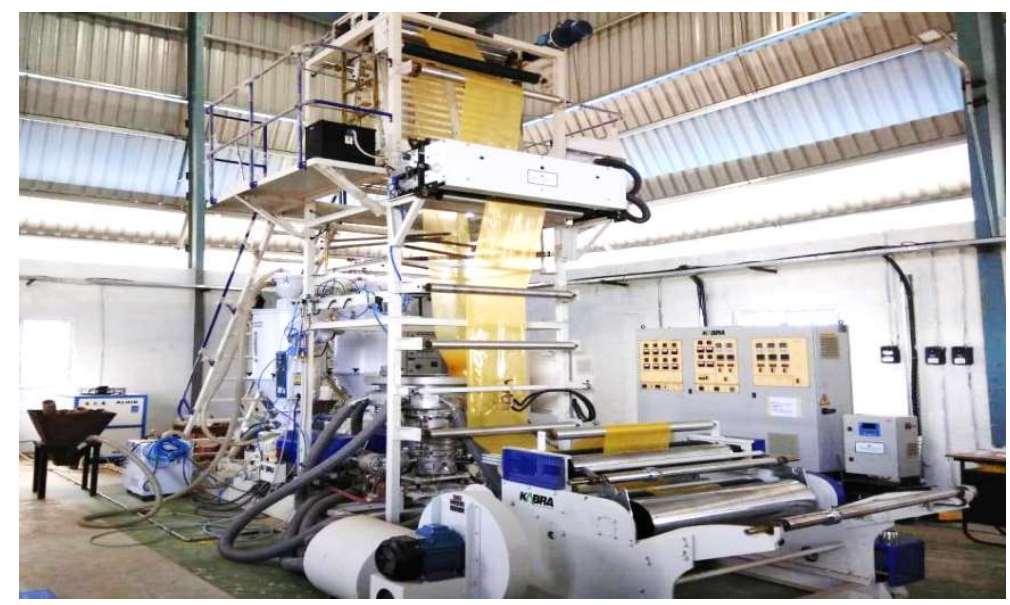

Figure 8: Plastic recycling plant at HiMSW P\&D facility Hyderabad

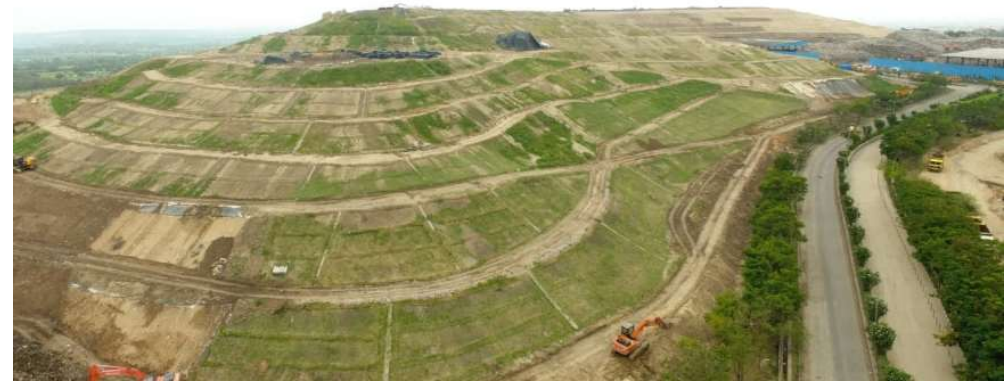

Figure 9: Landfill at HiMSW P\&D facility Hyderabad

\section{SUGGESTIONS}

An extensive survey was conducted to understand the characteristics of MSW across the country and mode of SWM operation in different parts of the nation. Based on the outcome the following conclusions are made-

- Segregation of MSW at source is possible only with some lucrative offers such as tax cuts, rewards, etc.

- More sophisticated vehicles with segregated collection systems need to be incorporated into the C\&T system.

- Transfer stations shall be automated with compaction based gravity loading system
- Better leachate management and security is required at the majority of the transfer stations.

- Stringent implementation of covered transportation is required to avoid spillage

- Vermicomposting is a lethargic process and not suitable for mixed MSW

- A separate system needs to be established to address moist coconut coir (such as pyrolysis)

- A shoe recycling system is required majorly in metropolitan cities

- Forced evaporation equipment such as MEE and ATFD is required to handle $\mathrm{RO}$ reject 
- Incineration ash shall be diverted to fruitful use from getting landfilled

\section{REFERENCE}

[1] Adipah S, Kwame ON (2019) A Novel Introduction of Municipal Solid Waste Management. Journal of Environmental Science and Public Health 3: 147-157. DOI: 10.26502/jesph.96120055

[2] Omran A, Gavrilescu M (2008) Municipal solid waste management in developing countries: A perspective on Vietnam. Environmental engineering and management journal 7: 469-478. DOI: $10.30638 /$ eemj.2008.070

[3] Miezah K, Obiri-Danso K, Kádár Z, Fei-Baffoe B, Mensah MY (2015) Municipal solid waste characterization and quantification as a measure towards effective waste management in Ghana. Waste Management 46: 15-27. DOI: 10.1016/j.wasman.2015.09.009

[4] Roy Choudhury A, Kumar NA, Arutchelvan V (2019) Integrated waste management through symbiotic culture: A holistic approach. IOP Conf. Ser.: Earth Environ. Sci. 344. doi:10.1088/1755$1315 / 344 / 1 / 012045$
[5] Banerjee S, Sarkhel P (2019): Municipal solid waste management, household and local government participation: a cross country analysis. Journal of Environmental Planning and Management, DOI: 10.1080/09640568.2019.1576512

[6] Roy Choudhury A, Gopalakrishnan D (2018) Proposed Waste Management Strategies for Small Pockets of Greater Hyderabad City: a Technical Review. International Journal of Creative Research Thoughts 6: 608-617.

[7] Municipal Solid Waste Management Manual Part II (2016). Central Public Health and Environmental Engineering Organisation (Cpheeo), Ministry of Urban Development, Government of India.

[8] Municipal Solid Waste Management Manual Part III: The Compendium (2016). Central Public Health and Environmental Engineering Organisation (Cpheeo), Ministry of Urban Development, Government of India.

[9] Parvez N, Agrawal A, Kumar A (2019) Solid Waste Management on a Campus in a Developing Country: A Study of the Indian Institute of Technology Roorkee. Recycling 4: 
1-22. DOI: 10.3390/ recycling 4030028

[10] Ahsan A, Alamgir M, El-Sergany MM, Shams S, Rowshon MK, Daud NNN (2014) Assessment of Municipal Solid Waste Management System in a Developing Country. Chinese Journal of Engineering Volume 2014: 1-11. DOI: $10.1155 / 2014 / 561935$

[11] Abdel-Shafy HI, Mansour MSM (2018) Solid waste issue: Sources, composition, disposal, recycling, and valorization. Egyptian Journal of Petroleum 27: 1275-1290. DOI: 10.1016/j.ejpe.2018.07.003

[12] Rumyantseva A, Berezyuk M, Savchenko N, Rumyantseva E (2017) Modern technologies of processing municipal solid waste: investing in the future. IOP Conf.
Series: Earth and Environmental Science 72: 012015. DOI: 10.1088/1755-1315/72/1/012015

[13] Roy Choudhury A, Kumar NA, Arutchelvan V (2017) A Review on Anaerobic Treatment in Decentralized and SourceSeparation-Based Sanitation Concepts: Applicability in Developing Countries. International Journal of Trend in Scientific Research and Development 1: 553-559.

[14] Al-Salem SM, Lettieri P, Baeyens J (2009) Recycling and recovery routes of plastic solid waste (PSW): A review. Waste Management 29: 2625-2643. DOI: 10.1016/j.wasman.2009.06.004 